\title{
Political Theory Simulations in the Classroom: Simulating John Locke's Second Treatise of Government
}

Derek Glasgow, University of Kansas

ABSTRACT Political scientists frequently use in-class simulations as teaching tools. However, few such exercises have been developed to assist in teaching pre-modern political theories. This is unfortunate because simulations effectively promote active learning and excite students about course material. This article develops a new simulation to teach Locke's Second Treatise of Government in an introductory general education or political science course. Surveys of participants indicate that the Locke simulation promotes active learning, as well as understanding of course concepts, teamwork, and interest in the material.

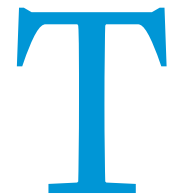
eaching political theory to undergraduates can be quite difficult. Frequently, political science and other liberal arts departments require the completion of courses exploring the philosophical roots of modern political theory by reading European Enlightenment political thinkers such as John Locke, Thomas Hobbes, and Jean Jacques Rousseau. However, students often view these types of classes and authors with disinterest and sometimes with reproach because they perceive these authors as esoteric and irrelevant.

Whereas many political scientists have used in-class simulations to make their subfields more interesting, few have used simulations in political theory classes. Scholars explored a variety of subfields such as American politics (Baranowski 2006), public policy (Endersby and Webber 1995), international relations (Ambrosio 2006), and comparative politics (Kaarbo and Lantis 1997). Several international relations theory simulations cover only some aspects of political theory, which consists mostly of diplomacy, negotiating, and explorations of international relations theory. However, scholars often neglect to create pre-contemporary political theory simulations (see Messner 1976 for one exception).

Past scholars indicate the ways in which in-class simulations promote student learning. Simulations promote critical thinking or "thinking outside the box" by presenting a series of problems to students and pushing them to experiment with, adapt, and alter in-game strategies and apply knowledge learned in lectures to find solutions (Shellman and Turan 2006). In addition, short in-class simulations, or working together in small groups to maximize learning and accomplish a common goal

Derek Glasgow is a graduate student in the department of political science at the University of Kansas. He can be reached at derek.john.glasgow@gmail.com. in which all members must complete a task, foster cooperative learning (Smith et al. 2005). Brief in-class simulations force students to use both their critical-thinking and problem-solving skills, as well as previous knowledge gained through lecture and reading, and apply them to simulation problems (Shellman and Turan 2006). Thus, in-class simulations promote critical skills.

Evidence from other academic fields indicates that simulations could also bolster enrollment in classes and programs in political theory that are marginalized in the field. In a survey of students in introduction to international relations courses, Shellman and Turan (2006) found evidence that suggests close to $20 \%$ of those students would change their majors to international relations after taking the researcher's class with simulations. Other scholars find that simulations enhance the enjoyment of the material (Shellman and Turan 2006). In a controlled experiment, economists found that students who participate in simulations do better on tests than those who are exposed to traditional lecture methods (Gremmen and Potters 1997). Research clearly documents both enhancement of learning and increased satisfaction from students partaking in these in-class simulations.

I argue that a simulation about John Locke's theories is one of many instruments that could promote student learning and help change the perception of the irrelevance of political theory in the modern era. Recently, rather than strengthening political theory programs, many universities threatened political theory programs with cutbacks (Rehfeld 2010). Therefore, if political theorists want to further their goals of increasing student interest and learning in political theory, simulations could be one tool in an overall plan for revitalization. More specifically, the following simulation is an engaging way for students to understand how John Locke's writing on property and individual rights, political cooperation, and the construction of representative governing institutions relate to the modern world. 


\section{JOHN LOCKE AND SECOND TREATISE OF GOVERNMENT}

One of the most popular books assigned in political theory/ philosophy is John Locke's Second Treatise on Government ${ }^{1}$, which provides a thorough explanation and summary of Locke's views.

In this work, Locke hypothesizes what people are like before the construction of political institutions. Before the existence of civil society, people are in a state of nature where individuals are equal (3), rational, able to restrain themselves (4-5), and take property (23). While the state of nature to Locke is relatively peaceful, there is potential for conflict between individuals because individuals also desire more property and possibly the property of others. Consequently, the state of nature can be punctuated by a state of war, which occurs when a person forgoes reason and "forces power" over another by taking away that person's freedom or property (11-12). To Locke, self-defense is justified in a state of war and individuals have the right of reciprocity or the right of defense from outside coercion (12). Therefore, the state of war is not an ideal environment in which individuals may develop property and attempt to find something more stable.

Locke asserts that people can avoid the state of war by forming a political society to prevent conflict, which is more preferable for individuals than the state of nature. According to Locke, a civil society governs individuals within the community that would
Although the game permits time changes, the estimated time length to complete the simulation is 30 to 40 minutes, plus a 10 to 15-minute debriefing. To conduct the simulation, a black board or marker board, or different colored chalk or markers, and movable chairs or desks within a view of the board are needed. The classroom space should be large enough so that the teams have some privacy to talk within their groups.

\section{Rules}

The first rule establishes that if any rule is intentionally broken, then that team loses all their squares and subsequently the game (see table 2).

As table 2 indicates, each team occupies a square in each corner of the board, which matches their number on the game grid. As long as a team has at least one square then they are still in the game. Negotiating between teams is permissible at any time, and teams are encouraged to appoint a diplomat to talk and establish agreements with other teams.

Next, the teacher should establish the goals and learning objectives of the game. Each team's goal is to acquire and protect the most squares at the end of the round. In the event of a tie, then all teams with the most squares win. ${ }^{2}$ The prize for the winner(s) can be anything from candy to extra credit.

\section{In the simulation framework, students interact with the assumptions of John Locke's state of nature, state of war, and the development of civil society as envisioned in his Second Treatise of Government.}

fully protect rights inherent in the state of nature. Individuals within a community consent to the rule of the majority through a social compact (or what he calls the "original compact") (59-6o), and laws created by this community protect property and the common good and defend the community (2). Locke's ideas of the formation of civil society offer a conceptual environment in which to construct a game in which students conclude that the formation of governing bodies to regulate their activities is preferable to the chaotic nature of an environment without political institutions.

\section{SIMULATION DETAILS}

In the simulation framework, students interact with the assumptions of John Locke's state of nature, state of war, and the development of civil society as envisioned in his Second Treatise of Government. The simulation allows students to place themselves in a situation where they can piece together the interrelated ideas of Locke into an interactive and collaborative environment. This simulation also provides an opportunity for students to build relationships with their classmates and hones their negotiation and critical-thinking skills.

To start the simulation, the teacher provides a basic overview of the simulation and the reading and copies of the game rules during or in advance of the simulation. Each individual draws a team number between one and four (see table 1). This simulation assumes four or more participants in each group, but it is possible for one person to be in a group. If there are more than 7 or 8 students in the group, the simulation may become too cumbersome because coordination within groups may be difficult.
After explaining the previous rules, the teacher should introduce only a portion of the turn rules. Students are told that each team gets one border move during their turn. However, the instructor secretly establishes a random number of turns in a round, as well as the number of rounds in a game. The teacher should manipulate the length of the simulation's number of rounds and games to fit with the length of the class, and inform students only when there are no rounds or games remaining. Creating this uncertainty is important: it shows students the value of institutions in solving the problem of uncertainty of the game length.

Students can do the following during a turn:

1. Invade an adjacent blank square (coloring the blank square the team's color)

2. Invade an adjacent square of another team (thereby declaring war). Erase and replace the square with the invading team's color.

3. Do nothing and pass (turn goes to the next team). Passing is only acceptable if the only move is to take another group's square; if there is a blank square, teams cannot pass.

4. Call an arbitration. Any active team can call for arbitration. It does not take up a turn and can occur anytime during a group's turn. If an arbitration is called, all teams are required to consent to the right of the teacher to propose rules and for the majority to approve them. If this first stage of arbitration passes, then the teacher will declare a rule addition or change. For arbitration to pass, a majority (or three groups) has to consent to the rule change. 
Table 1

\section{Overview of Locke Simulation}

\begin{tabular}{ll} 
Number of participants & Four teams (recommended 1-4 students on each team) \\
\hline Estimated time & Depends on randomization of length of Rounds and Games (recommended 30-40 minutes) \\
\hline Temporal Elements & One round (4 turns). One game (to be determined by number of rounds). \\
\hline Materials Required & Blackboard, markers, movable chairs (ideal) \\
\hline Objective & Team(s) with the most squares wins. All teams with most squares win.
\end{tabular}

The simulation ends in a few ways. First, if all teams decide to pass in a round, then the game ends. Second, the simulation could run out of time by reaching the last round in a game. Finally, after a successful first stage of arbitration vote, the teacher proposes a rule to prevent the seizing of property and the majority of teams consent, and thereby reaching a natural equilibrium to the game after all groups acquire available property.

\section{Expectations}

After a few rounds, students should begin to understand that it is in their best interest to cooperate across teams by establishing rules and norms to prevent the perpetual state of war that they could inflict on one another. Teams who do not start conflicts with others tend to do better than those who do.

As rounds progress, teams could realize that not attacking others, acquiring four squares, and then passing is the best way for all teams to win (as demonstrated in table 3, all teams tie for first, therefore, all teams win). However, rarely do all teams come to this rational conclusion.

Some students may figure out the most rational strategy and attempt to spread this idea to other teams. Teachers should be cognizant of this because this could potentially shorten the simulation and thus prevent a robust way of showing Locke's beliefs about the development of civil society. If the teacher perceives game time length as an issue, then the number of turns/rounds of the game can be changed or one team can be secretly convinced

\section{Table 2 \\ Simulation Structure}

\begin{tabular}{l|l|l|l} 
Team 1 & & & Team 3 \\
\hline & & & \\
\hline Team 2 & & & \\
\hline
\end{tabular}

Table 3

Ideal Equilibrium

\begin{tabular}{l|c|c|c} 
Team 1 & Team 1 & Team 3 & Team 3 \\
\hline Team 1 & Team 1 & Team 3 & Team 3 \\
\hline Team 2 & Team 2 & Team 4 & Team 4 \\
\hline Team 2 & Team 2 & Team 4 & Team 4 \\
\hline
\end{tabular}

to develop a hostile strategy toward others. However, in all of the tests of this simulation, the competitive nature of students prevented initial cooperation between groups. Students who desired to adopt a rational strategy found it difficult to convince out-group members of this strategy because of potential trust issues inherent in a competitive game environment.

Ideas about developing allies and coordinating attacks against another group(s) may seem like the optimal strategy for some groups; however, in the end, war with other factions is not advantageous. Attacked groups retaliate and the amount of squares obtained by conquest minimizes overall rewards for structured teamwork. Also, after repeated turns and rounds, teams are uncertain when the game could end, and alliances do not necessarily guarantee that a team's property is equal to or more than the number of their ally's squares.

Early in the game, a sort of equilibrium between teams seems to be common, and certain strategies develop to respond to those who upset peace between groups. One common team strategy is to punish those teams who initiate acts of war on others by seizing their property. This sort of tit-for-tat maneuver occurs when teams respond by recovering their property and continue to take that the offending team's property in future turns. Other groups not involved in the dispute may also punish teams for being aggressive and upsetting the general harmony of previous turns. A social norm may develop when teams view an attack on one team as an attack on all. Despite these social expectations, students find it increasingly difficult to follow this rule when empty squares become scarce. Because the goal of the game is to acquire the most property, teams have to decide between violating this expectation and further square acquisition.

\section{Debriefing}

After the game ends, the teacher should debrief participants on the parallels of the simulation and John Locke's work. A lecture on Locke and the simulation could show how these both match. Also, an informal discussion or giving students questions to answer in an assignment or in discussion could help students make these connections. These activities should address and deconstruct major course themes and learning objectives.

The structure and events of the simulation mirror the concepts and expectations of John Locke. This becomes apparent during the state-of-nature phase of the simulation. Early in the game, each team starts out with one square on a symmetrical board and the rules apply equally to all teams, which represents Locke's idea of the state of perfect equality in the state of nature and undeveloped property. The acquisition of more squares on the game board also imitates what Locke viewed as God's command to and people's need to appropriate property. 
The likelihood of conflict and a state of war becomes clear as the game progresses. The ability of teams to invade and take the squares of another team characterizes the state of war that individuals declare against others when attempting to harm another's life or property. Students work toward the development of new rules through arbitration that prevent the taking of squares, which matches Locke's belief that the preservation of one's life and property through political institutions is ideal. about the development of civil society, and teams may not reach optimal solution for all teams. The punctuation of the state of nature by the state of war could be constant.

\section{ASSESSMENT OF SIMULATION}

To gauge the effectiveness of the simulation, a survey of past simulation participants was conducted. More than 100 University of Kansas undergraduates in six different Humanities and

\section{Students work toward the development of new rules through arbitration that prevent the taking of squares, which matches Locke's belief that the preservation of one's life and property through political institutions is ideal.}

The simulation also mirrors the duality of Locke's belief about cooperation between individuals. The incentive structure of the simulation reflects his conception of human's transition from the state of nature to the creation of civil society. Participants should conclude that the best way to reach an optimal outcome for all players is to either initially cooperate without any formal arrangements or eventually develop a deliberative body with the teacher as the arbiter.

To quell in-game conflicts, players use in-game arbitration, new rules, and cooperation, which echoes Locke's ideas about the development of civil society. The creation of a social compact and the formal consent of the majority to abide by a monarch's rules parallels simulation groups consenting to the authority of the majority and the arbiter's new game rules. The cooperation between teacher and students in shared decision-making powers is similar to how Locke views the separation of powers in constitutional monarchy.

Students also may become critical of Locke's work and challenge the assumptions of some aspects of the simulation. Students may ask this question: if people are rational in the state of nature, then why do they need to create institutions in the first place? While Locke addresses this by arguing that individuals can "forgo" their rationality and declare war, then students may question the tenability of Locke's definition of human rationality and reason. Students may also be skeptical of Locke's arguments
Western Civilization 205 classes consisting of 15 to 20 participants participated in this simulation during discussion classes. In the summer of 2013, 45 of these participants were surveyed.

Overall, the simulation is successful at obtaining the interest of students and promoting their learning. Table 4 indicates more than two-thirds of students were interested and enjoyed participating in the simulation, believed it promoted cooperation, and helped them learn about Locke. 3

Students also contend that the structure of the simulationhaving a facilitator and using one class period-is appropriate for this simulation. Quotations on student evaluations also indicate the effectiveness of the Locke simulation in student learning. For example, students would comment on the simulation's ability to engage students. "I liked the simulations because they got the class more involved for than just discussion." Students also indicate it helped to understand Locke. "Simulations were fun and helped me to better understand material." Therefore, both qualitative and quantitative assessments indicate that the simulation is successful in promoting student learning.

\section{POTENTIAL MODIFICATIONS OF THE SIMULATION AND EXPANSION}

The advantage of a single-class simulation is that it is specific enough to allow investigation of one single topic in a single class

Table 4

Survey Questions

\begin{tabular}{|c|c|c|c|c|c|}
\hline & Strongly Disagree & Disagree & Neither Agree/Disagree & Agree & Strongly Agree \\
\hline I found this simulation interesting & 0 & 0 & 3 & 33 & 7 \\
\hline I enjoyed participating in this simulation & 0 & 1 & 6 & 22 & 5 \\
\hline $\begin{array}{l}\text { This simulation helped me to better understand } \\
\text { theories and concepts related to Locke }\end{array}$ & 0 & 3 & 7 & 16 & 6 \\
\hline $\begin{array}{l}\text { Allotting one class period for this assignment } \\
\text { was about the right amount of time }\end{array}$ & 0 & 4 & 3 & 20 & 6 \\
\hline $\begin{array}{l}\text { The simulation promoted in-group discussion } \\
\text { and cooperation }\end{array}$ & 0 & 1 & 2 & 22 & 8 \\
\hline $\begin{array}{l}\text { Having a facilitator for the simulation exercise } \\
\text { aided in my learning }\end{array}$ & 0 & 0 & 7 & 16 & 14 \\
\hline $\begin{array}{l}\text { Having a facilitator for the simulation exercise } \\
\text { made it more organized }\end{array}$ & 1 & 0 & 4 & 24 & 12 \\
\hline
\end{tabular}


session, but it is versatile enough to allow multiple variations. When reflecting on the logic of this simulation, other possible paths from the basic logic of the simulation are possible. One philosophers now and in the future. Simulations offer departments and teachers one way to show that theory is not a dead field.

\section{The advantage of a single-class simulation is that it is specific enough to allow investigation of one single topic in a single class session, but it is versatile enough to allow multiple} variations.

possible outcome to this simulation is that students do not reach a cooperative agreement. Teachers can use this result as an example supporting Thomas Hobbes's claim that the state of nature is a state of war (Hobbes 1994). In addition, because the basic structure of the game board is versatile, many other permutations are possible. Teachers could incorporate different values to the squares of the board. This manipulation of the game board could push students to never come to an agreement because the structure of the game does not produce an ideal outcome for all students, which would result in a similar result to the outcome of Hobbes's state of nature. Other possible alternatives or expansions of this simulation could consist of students constructing a similar simulation themselves based on the beliefs of other political theorists. All of these approaches could allow students to compare and contrast the arguments of Enlightenment political theorists (Locke, Hobbes, Rousseau) and other course concepts (e.g., social contract theory and prisoner's dilemma) covered in the course in a unique manner with a basic simulation on which to build.

\section{CONCLUSION}

Both political science departments and students can benefit from simulations like the one presented in this study. Political theorists often have difficulty engaging students with their course material, but this Locke simulation is an effective tool for engaging students and promoting critical skills. Theory instructors should not be concerned about time constraints when constructing their own in-class simulations because this simulation was developed in only a few hours. With such a minor time commitment, teachers should see tremendous benefits from using in-class simulations for other political

\section{NOTES}

1. The following paraphrasing comes from Locke, John. 1982. "Second Treatise of Government, Edited by R. H. Cox." Harlan Davidson, Arlington Heights, Il.

2. It is important to note that students will eventually realize that all teams winning is the key to continued success for each team after each game. It is important that the teacher allow the students to reach this point on their own.

3. Survey questions modified from "Synergy cross the Curriculum; Simulating the Institution of Postwar Iraqi Government" by Austin et al (2006).

\section{REFERENCES}

Ambrosio, T. 2006. "Trying Saddam Hussein: Teaching International Law through an Undergraduate Mock Trial.” International Studies Perspectives 7: 159-71.

Austin, W. C., et al. (2006). "Synergy across the curriculum: Simulating the institution of postwar Iraqi government." Journal of Political Science Education 2 (1): 89-112.

Baranowski, M. 2006. "Single Session Simulations: The Effectiveness of Short Congressional Simulations in Introductory American Government Classes." Journal of Political Science Education 2: 33-49.

Endersby, J. W., and D. J. Webber. 1995. "Iron Triangle Simulation: A Role-Playing Game for Undergraduates in Congress, Interest Groups, and Public Policy Classes." PS: Political Science and Politics 28: 520-23.

Gremmen, H., and J. Potters. 1997. "Assessing the Efficacy of Gaming in Economic Education." The Journal of Economic Education 28: 291-303.

Hobbes, T. 1994. Leviathan, Edited by Edwin Curley. Indianapolis, IN: Hackett Publishing Company.

Kaarbo, J., and J. S. Lantis. 1997. "Coalition Theory in Praxis: A Comparative Politics Simulation of the Cabinet Formation Process." PS: Political Science and Politics 30: 501-06.

Locke, John. 1982. Second Treatise of Government, Edited by R. H. Cox, Arlington Heights, IL: Harlan Davidson.

Messner, M. 1976. "Bubblegum and Surplus Value." Critical Sociology 6: 51-56.

Rehfeld, A. 2010. "Offensive Political Theory." Perspectives on Politics 8: 465-86.

Shellman, S. M., and K. Turan. 2006. "Do Simulations Enhance Student Learning? An Empirical Evaluation of an Ir Simulation." Journal of Political Science Education 2: $19-32$.

Smith, Karl A., Sheri D Sheppard, David W Johnson, and Roger T. Johnson. 2005 "Pedagogies of Engagement: Classroom-Based Practices." Journal of Engineering Education 94: 87-101. 